\title{
On the Survival of Frozen Bacteria
}

\author{
By J. R. POSTGATE AND J. R. HUNTER \\ Microbiological Research Establishment, Porton, Wiltshire, England
}

(Received 9 February 1961)

\section{SUMMARY}

Steadily growing Aerobacter aerogenes organisms were largely killed by slow freezing in buffer or by freeze drying. $100 \%$ survival was obtained after dropping bacteria suspended in $10 \%$ aqueous glycerol into liquid nitrogen and thawing. Ten per cent solutions of diethylene glycol, $i$-erythritol, glucose, sucrose or polyethylene glycol $(M W=10,000)$ protected equally well; the last three substances did not penetrate the cell cytoplasm. The most lethal medium was dilute $\mathrm{NaCl}$; broth, water or a dilute salt mixture were moderately lethal. These findings are incompatible with the view that the lethal effects of freezing are connected with osmotic shock or that protection from freezing damage requires $(a)$ penetration of the protective agent or (b) osmotic dehydration of the cytoplasm. Cells frozen and thawed, even with a protective agent, showed a lowered rate of glycerol oxidation and a higher death rate when starved at the optimal temperature and $\mathrm{pH}$ value for growth. The storage life of frozen organisms at $-20^{\circ}$ depended on the protective agent used; only glycerol permitted extended storage.

\section{INTRODUCTION}

Rapid chilling of microbial suspensions by dropping them into liquid nitrogen has been used by some workers as a means of disrupting the organisms. Moses (1955) obtained preparations of citric acid cycle enzymes from the mould Zygorrhynchus moelleri in this manner; Postgate (1960) used it to obtain a particulate sulphite reductase preparation from Desulfovibrio desulfuricans; Wade \& Lovett (1961) extracted ribonucleic acid from Escherichia coli type B by such a procedure. Paradoxically, however, a considerable volume of reports exists demonstrating that bacteria survive chilling to very low temperatures. Earlier work was reviewed by Luyet \& Gehenio (1940), who pointed out that much of the data were not quantitative, but who recorded figures as divergent as $11 \%$ kill with $E$. coli in broth frozen to $-78^{\circ}$ (Sanderson, 1925) to $99.98 \%$ kill of Bacterium typhosum (Salmonella typhi) in broth (Smith \& Swingle, 1905) after freezing at $-17 \cdot 8^{\circ}$. Haines (1938) obtained only $5 \%$ killing of a staphylococcus by freezing in solid $\mathrm{CO}_{2}$ and kills of other micro-organisms were small. Wieser \& Osterud (1945) recorded modest kills of E. coli on freezing (15\% at $-2^{\circ}, 50 \%$ at $-5^{\circ}$ or $-10^{\circ}$ ); Straka \& Stokes (1959) reported about $10 \%$ kills of $\boldsymbol{E}$. coli and pseudomonads on freezing in beef broth; Wood \& Rosenberg (1957) recorded $100 \%$ survival of yeast frozen in phosphate buffer at $-60^{\circ}$. Mazur, Rhian \& Mahlandt (1957) reported that slow chilling and rapid warming afforded maximum survival of Pasteurella tularensis frozen in 'gelatin saline' to temperatures between $-10^{\circ}$ and $-70^{\circ}$. In all circumstances rather low survivals compared with unfrozen 
controls were obtained, but Mazur (1960) mentioned an experiment in which the addition of sucrose or lactose $(0.3 \mathrm{M})$ permitted nearly $100 \%$ survival after slow cooling and slow warming.

Harrison \& Cerroni (1956) recorded very slight killing of Microbacterium flavum on repeated freezing to $-\mathbf{2 2}^{\circ}$ and thawing; Escherichia coli showed much greater sensitivity though both species were about equally sensitive to mechanical damage. Major, McDougal \& Harrison (1955) studied the survival of various bacteria stored frozen in broth at $-\mathbf{2 2}^{\circ}$ and showed that in most instances the survival was longer the denser the initial population; their data did not include survivals measured immediately after freezing except in the case of $\boldsymbol{E}$. coli frozen in distilled water, which then showed a small (about 10\%) kill and no population effect. Record \& Taylor (1953) failed to observe a population effect with $E$. coli frozen in phosphate buffer at $-78^{\circ}$ and thawed at once (kill $40 \%$ ). Harrison (1955) showed that the population effect did not occur with Lactobacillus fermenti after a single freeze and thaw (about $90 \%$ kill) but that it was manifest after repeated freezing and thawing with intervals of storage. Aeration influenced the resistance of $\boldsymbol{E}$. coli to freezing in a complex manner. Harrison (1956) studied the influence of environment on freezing three bacterial species at $-\mathbf{2 2}^{\circ}$ and showed that broth was a more lethal environment for freezing than was distilled water. Suspensions chilled to $-\mathbf{2 2}^{\circ}$ but prevented from freezing with $\mathrm{NaCl}(4 \cdot 6 \mathrm{M})$ or glycerol $(4 \cdot 1 \mathrm{M})$ had similar store lives to frozen suspensions.

Hollander \& Nell (1954) showed that addition of $15 \%$ glucose to broth permitted $100 \%$ survival of Escherichia coli, Diplococcus pneumoniae, Treponema pallidum and probably of Rhodospirillum rubrum. They considered the protective effect of glycerol to be analogous to its action on bull spermatozoa (Polge, Smith \& Parkes, 1949) or erythrocytes (Lovelock, 1953). Howard (1956) used a frozen glycerol broth according to Hollander \& Nell's prescription to preserve cultures of bacteria; so did Tanguay (1959) and Floodgate \& Hayes (1961). Fox \& Hotchkiss (1957) used freezing in aqueous glycerol to preserve pneumococci in a receptive state for transforming deoxyribonucleic acid. None of these workers quoted quantitative data on survival after freezing. Squires \& Hartsell (1955) reported some quantitative data on the survival of $E$. coli after freezing at $-25^{\circ}$ and storage at $-9^{\circ}$; as an additive $5 \%$ glycerol was superior to gelatin and a vegetable oil for organisms frozen in a buffered broth. Quadling (1960) reported $100 \%$ survival of Xanthomonas phaseoli on freezing in strong glycerol broth, though exposure of the organisms to this medium killed about $60 \%$ of the population without freezing.

In the course of other studies we wished to preserve populations of steadily growing Aerobacter aerogenes while retaining as nearly as possible $100 \%$ viability, and we performed a number of experiments on deep freezing. These are reported below, since they have some relevance to the question of freezing damage and were performed on a single culture of the same organism in a phase of growth analogous to the logarithmic phase, commonly associated with enhanced sensitivity to stresses of various kinds including freezing (Toyokama \& Hollander, 1956); in addition they deal largely with survival in solutions of single pure substances. 


\section{METHODS}

Aerobacter aerogenes, obtained from Professor Sir Cyril Hinshelwood's laboratory, had been maintained for some 18 months in continuous aerobic culture in a defined $(0 \cdot 2 \%, w / v)$ glycerol medium analogous to that used for Cloaca cloacae by Herbert, Elsworth \& Telling (1956). We shall describe the cultural conditions and history of the strain in more detail elsewhere; for present purposes it is sufficient to record that the dilution rate was $0.25 \mathrm{vol} . / \mathrm{hr}$., $\mathrm{pH} 7 \pm 0 \cdot 1,40^{\circ}$; growth limited by glycerol concentration to $1.05 \pm 0.05 \mathrm{mg}$. dry wt. organism $/ \mathrm{ml}$. This corresponded to a viable count of about $2 \cdot 4 \times 10^{9}$ organisms $/ \mathrm{ml}$, equal to the total count determined by a combination of microscopy and interferometry (Norris \& Powell, 1961).

Viability was determined by slide culture at $37^{\circ}$ (Postgate, Crumpton \& Hunter, 1961) on the growth medium supplemented with yeast extract (Difco, 0.1\%, w/v), casein hydrolysate (Difco, $0.1 \%, \mathrm{w} / \mathrm{v})$, a tryptic meat broth $(10 \%, \mathrm{v} / \mathrm{v}$ ) and set with agar $(1.5 \%, w / v)$. The nitrogenous supplements should have ensured growth of 'nutritionally injured' organisms of the type demonstrated by Straka \& Stokes(1959). Before slide culture, frozen populations were thawed by diluting in 50 or 500 vol. saline phosphate buffer ( 9 parts $0 \cdot 137 \mathrm{M}-\mathrm{NaCl}+1$ part of a $1: 5$ mixture of $0.066 \mathrm{M}$ -

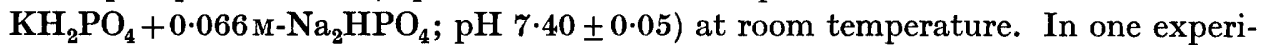
ment death curves were measured in a saline 'tris' buffer $(9$ parts $0 \cdot 137 \mathrm{Mr}-\mathrm{NaCl}+$ 1 part $0 \cdot 048 \mathrm{M}-2$-amino-2-hydroxymethylpropane-1:3-diol ('tris') +0.316 mM ethylenediaminetetra-acetic acid (EDTA); $\mathrm{pH} 7 \cdot 00 \pm 0 \cdot 05)$. Reagents of analytical grade were used except that $i$-erythritol and $\mathbf{D}$-glucose were 'bacteriological' sugars, diethylene glycol was a re-distilled (b.p. 135-137 ) specimen kindly provided by Major L. H. Kent, polyethylene glycol was a well-dialysed, freeze-dried preparation of mean mol. wt. 10,000 kindly provided by Dr B. R. Record. Water was distilled and then de-ionized by treatment with a mixed bed ion exchange resin. Percentages recorded in this paper are $\mathrm{w} / \mathrm{v}$ except in the cases of glycerol and diethylene glycol when they are $\mathrm{v} / \mathrm{v}$.

\section{RESULTS}

\section{Sensitivity of the population to cold}

Gram-negative bacteria in the logarithmic phase of growth are sometimes killed by cold shock even when no freezing takes place (Sherman \& Cameron, 1934; Hegarty \& Weeks, 1940). This phenomenon requires a 'toxic' suspending fluid of low osmotic pressure (Meynell, 1958) and is not shown by staphylococci (Gorrill \& McNiel, 1960). The population of Aerobacter aerogenes used in this work did not show appreciable cold shock of this kind. Organisms harvested from the culture chamber, washed by centrifugation in $0.8 \% \mathrm{NaCl}$ and diluted into cold buffer showed $99 \%$ viability in saline phosphate buffer at room temperature, $98 \%$ at $4^{\circ}, 94 \%$ after squirting on to frozen buffer at its melting point. Suspensions were, however, killed when $10 \mathrm{ml}$. portions in tubes were frozen in solid $\mathrm{CO}_{2}$ : the initial viability fell from $96 \%$ to less than $1 \%$ in these conditions. Use of mist. desiccans (Fry \& Greaves, 1951) in place of buffer afforded no protection $(\mathbf{9 3 . 8} \%$ viable population fell to less than $0.3 \%$ after freezing in mist. desiccans with solid $\mathrm{CO}_{2}$ ). Effluent from the continuous culture freeze-dried without further treatment fell from about 98 to $5 \%$; centrifugation and resuspension in mist. desiccans provided no significant protection (viability fell to 
$6 \%$ ). The low survivals obtained in these conditions are probably attributable to our use of organisms in what corresponds to a logarithmic phase of growth. Organisms re-suspended in the original medium (containing $0.2 \%$ glycerol) and freeze-dried had the marginally greater viability of $10 \%$.

\section{Protection from killing by freezing}

A thick suspension (equiv. about $50 \mathrm{mg}$. dry wt. organism/ml.), resuspended in a salt mixture corresponding to the growth medium without glycerol, was allowed to drop from a pipette into liquid nitrogen, so that the suspension froze as discrete beads. These were allowed to thaw to room temperature and showed $35 \%$ viability. This observation suggested that deep freezing might provide a method of preserving the population, and the viability (in various suspending media) after deep freezing with liquid nitrogen was studied. Organisms were harvested from the continuous culture, centrifuged and made up as suspensions equivalent to 1 or $10 \mathrm{mg}$. dry wt. organism $/ \mathrm{ml}$. Within 5-15 min. these were frozen as beads of about $0.05 \mathrm{ml}$. by dropping from a pipette into liquid nitrogen. This procedure took 1-2 sec. The beads were then removed after 3 to $10 \mathrm{~min}$. with cold forceps and thawed by dropping into 25 or $\mathbf{2 . 5}$ ml. saline phosphate buffer at room temperature. This procedure adjusted the population density to a value suitable for slide culture; thawing in these conditions took 2-3 sec.

Table 1 records a representative set of experiments. Suspension in $10 \%$ aqueous glycerol protected all the viable organisms from killing by freezing $(1 b ; 2 a, b, c)$; there was no population effect of the kind reported by Major et al. (1955) over a 100fold range of suspension concentrations $(1 c, d ; 2 a, b, c)$. A tryptic broth of meat allowed considerable killing $(4 f)$; glycerol as prescribed by Hollander \& Nell (1954) protected the organisms from the toxicity of broth $(4 \mathrm{~g})$. Unlike the organisms studied by Major et al. (1955), Harrison (1956) and Clement (1961), considerable kills of our bacteria occurred on freezing in distilled water $(1 a)$; comparable kills were obtained when suspensions equivalent to $1 \mathrm{mg}$. dry wt. organism $/ \mathrm{ml}$. were frozen and thawed in (i) distilled water which had not been treated with resin (viability: 58\%), (ii) water distilled twice, the second time from glass (viability : $67 \%$ ), (iii) the distilled and resintreated water usually used in this work (viability: $68 \%$ ) or (iv) our local tap water (viability: 53\%). Sodium EDTA (10 mM) had no significant effect on the kill (viability: $42 \%$ with EDTA, $49 \%$ without). These experiments make it unlikely that impurities in the distilled water or population effects contributed to the kill. Carryover of salts in the washing procedure likewise did not account for the kill, since a suspension repeatedly centrifuged in distilled water gave 68,47 and $48 \%$ viabilities after the first, second and third centrifuging; the unfrozen control was $98 \%$ viable after the third centrifuging.

$\mathrm{NaCl}$ solutions were the most lethal environments encountered and the kill after freezing and thawing was independent of the salt concentration over a wide range $(5 a-e)$. Buffered sodium chloride with 'tris' made little difference $(5 f)$, but phosphate had a marginal protective effect $(5 \mathrm{~g})$ and probably accounts for the lowered kill in the substrate-free medium $(1 c, d)$ which was essentially a phosphate mixture with trace elements. Addition of glycerol to the medium afforded partial protection ( $1 e)$. Harrison (1956) showed that glycerol protected organisms frozen in salt solutions. 
Glycerol at $10 \%$ also protected stationary phase organisms harvested from an agar slope (3a).

The glycerol concentration could be reduced to $2 \%$, but not below this value, without losing its protective effect. It could be replaced by $10 \%$ aqueous solution of diethylene glycol $(4 a)$, glucose $(4 b), i$-erythritol $(4 e)$, sucrose $(4 c)$ and a polyethylene glycol of mean molecular weight $10,000(4 d)$. Though some of these solutions had slight intrinsic toxicities, lowering the initial viability of the population from about 97 to about $90 \%$, the survivors were wholly protected from freezing. The molarities of these solutions were: glycerol, $1.08 \mathrm{M}$; diethylene glycol, $0.93 \mathrm{M}$; $i$-erythritol, $0.82 \mathrm{M}$; glucose, $0.55 \mathrm{M}$; sucrose, $0.29 \mathrm{M}$; polyethylene glycol, $0.01 \mathrm{M}$.

\title{
Table 1. Viabilities of suspensions of Aerobacter aerogenes after a single freeze and thaw
}

\begin{abstract}
Aerobacter aerogenes growing at an imposed doubling time of $2.8 \mathrm{hr}$. in continuous culture were centrifuged, drained and re-suspended in the solutions indicated at about equiv. $10 \mathrm{mg}$. dry wt. organism/ml. in experiments 1 and 2, equiv. $1 \mathrm{mg}$. organism/ml. in experiments 3, 4 and 5. Drops (about $0.05 \mathrm{ml}$.) of suspension were frozen in liquid nitrogen diluted in buffered saline and the \% viable organism determined by slide culture.
\end{abstract}

\begin{tabular}{|c|c|c|c|}
\hline \multirow[b]{2}{*}{ Experiment } & \multirow[b]{2}{*}{ Medium } & \multicolumn{2}{|c|}{ Viability (\%) } \\
\hline & & Control & Frozen \\
\hline $1 a$ & Distilled water & 97 & 63 \\
\hline $1 b$ & Aqueous $10 \%$ glycerol & 97 & 96 \\
\hline $1 c$ & Basal medium without carbon source & 97 & 39 \\
\hline $1 d$ & As $1 c$ but equiv. $1 \mathrm{mg}$. dry wt. organism $/ \mathrm{ml}$. & 97 & 32 \\
\hline Ie & Basal medium $+10 \%$ glycerol & 97 & 70 \\
\hline $2 a$ & $10 \%$ glycerol & 97 & 96 \\
\hline $2 b$ & As $2 a$, but equiv. $1 \mathrm{mg}$. dry wt. organism $/ \mathrm{ml}$. & 97 & 95 \\
\hline $2 c$ & As $2 a$ but $0.1 \mathrm{mg}$. organism $/ \mathrm{ml}$. & 97 & 95 \\
\hline $3 a$ & $\begin{array}{l}10 \% \text { glycerol ; stationary phase organisms from agar } \\
\text { slope }\end{array}$ & 90 & 89 \\
\hline $4 a$ & $10 \%$ diethylene glycol & 97 & 95 \\
\hline $4 b$ & $10 \%$ glucose & 91 & $\mathbf{8 8}$ \\
\hline $4 c$ & $10 \%$ sucrose & 98 & 95 \\
\hline $4 d$ & $10 \%$ polyethylene glycol, mol. wt. about 10,000 & 92 & 89 \\
\hline $4 e$ & $10 \% i$-erythritol & 97 & 95 \\
\hline $4 f$ & Tryptic meat broth & 93 & 48 \\
\hline $4 g$ & As $4 f+15 \%$ glycerol & 92 & 91 \\
\hline $5 a$ & $\mathrm{M}-\mathrm{NaCl}(5.6 \%)$ & 95 & 12 \\
\hline $\mathbf{5} b$ & $0.4 \mathrm{M}-\mathrm{NaCl}$ & 97 & $\mathbf{5}$ \\
\hline $5 c$ & $0 \cdot 1 \mathrm{MI}-\mathrm{NaCl}$ & 97 & 11 \\
\hline $5 d$ & $0.05 \mathrm{M}-\mathrm{NaCl}$ & 96 & 25 \\
\hline $5 e$ & $0.005 \mathrm{M}-\mathrm{NaCl}$ & 96 & 23 \\
\hline $5 f$ & 'Saline tris buffer' & 98 & 15 \\
\hline $5 g$ & 'Saline phosphate buffer' & 99 & 36 \\
\hline
\end{tabular}

An illusion of high viability could have occurred if freezing had induced lysis of the suspensions before the organisms were spread on the agar films for slide culture. No signs of lysis were observed on the slide cultures, and if such lysis had been significant it should have been detectable as an optical density change on thawing a frozen suspension. This was not observed: a suspension equiv. $\mathbf{2 \cdot 2} \mathbf{~ m g}$. dry wt. organism $/ \mathbf{m l}$. $10 \%$ glycerol had an optical density reading $(540 \mathrm{~m} \mu)$ of 0.258 on dilution (1 vol. 10) in $0.85 \% \mathrm{NaCl}$; a portion of the same suspension frozen in liquid nitrogen and thawed before dilution had an optical density of $\mathbf{0 \cdot 2 6 2}$. 


\section{Effect of freezing on physiology}

Other work in our laboratory has shown that populations of logarithmic phase Aerobacter aerogenes grown as described here have an initially linear death rate at their growth temperature and $\mathrm{pH}$ value in a non-nutrient buffer (see Postgate $e t$ al. 1961; Fig. 1). Glycerol and other substrates which the organisms metabolize affect the death rate, but diethylene glycol, which is not utilized by this strain, had no effect at all up to $\mathbf{0 . 2} \%$. The innocuous nature of diethylene glycol enables one to test the effect of deep freezing upon subsequent death. A suspension equiv. $1 \mathrm{mg}$.

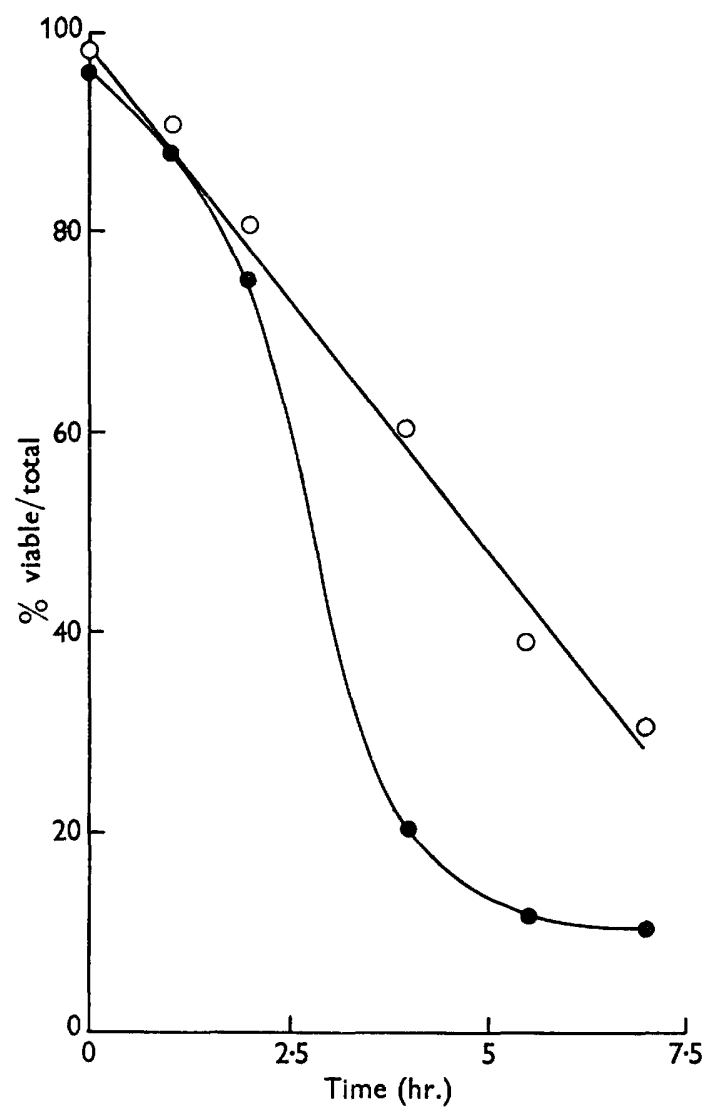

Fig. 1. Death rate of frozen and thawed Aerobacter aerogenes. A. aerogenes (equiv. $1 \mathrm{mg}$. dry wt. organism/ml.) grown as in Table 1 were washed by centrifugation, frozen in $10 \%$ diethylene glycol at $-200^{\circ}$, thawed, diluted 50 -fold and aerated in saline 'tris' buffer ( $\mathrm{pH}$ $7 \cdot 00 \pm 0.05$ ) at $40^{\circ}$ (the growth temperature and $\mathrm{pH}$ value). Viabilities were determined by slide culture; the control was a similar suspension not frozen. $O$, Control; $\bullet$, frozen and thawed cells.

dry wt./ml. $10 \%$ diethylene glycol was divided in two and one portion frozen in liquid nitrogen and thawed. One ml. of each was diluted into $50 \mathrm{ml}$. non-nutrient buffer (diethylene glycol finally $0.2 \%$ ) and incubated with aeration at $40^{\circ}$. Figure 1 shows the viability of samples taken at intervals: the population died more rapidly after deep freezing in the glycol, though the initial viabilities were similar. 
Deep freezing might affect the respiratory system. A population (equiv. $10 \mathrm{mg}$. dry wt./ml.) frozen in $10 \%$ glycerol was thawed in 10 vol. saline phosphate and the $\mathrm{Q}_{\mathrm{O}_{2}}$ determined manometrically at $40^{\circ}$; it was $-183 \mu \mathrm{l} . \mathrm{O}_{2} / \mathrm{mg}$. $/ \mathrm{hr}$. A control treated similarly but stored at $-4^{\circ}$ in glycerol during the freezing and thawing had a $Q$ value of $-229 \mu \mathrm{l} . \mathrm{O}_{2} / \mathrm{mg}$. $/ \mathrm{hr}$. In a second experiment the respective values were -243 and $-325 \mu \mathrm{l} . \mathrm{O}_{2} / \mathrm{mg}$. hr.

\section{Effect of rate of freezing on survival}

Mazur et al. (1957) reported that maximum survival of Pasteurella tularensis was obtained with slow freezing and rapid warming. In our studies warming was always as rapid as practicable. Some crude experiments were undertaken to seek any effect of freezing rate: $\mathbf{0} .2 \mathrm{ml}$. of a suspension (equivalent to $1 \mathrm{mg}$. dry wt. $/ \mathrm{ml}$.) in $10 \%$ glycerol was frozen in a deep freezer at $-20^{\circ}$ (taking $3 \pm 1$ min. to solidify) beside $\mathbf{2 \cdot 3} \mathrm{ml}$. of a similar suspension (which took about $20 \mathrm{~min}$. to solidify). The specimens were deliberately placed where freezing would be slow. No differences among the viabilities were observed: control, $98 \%$; quickly frozen suspension, $98 \%$; slowly frozen, $97 \%$. Freezing in liquid nitrogen by the procedure we routinely used took 1-2 sec.; freezing in isopentane chilled to $-190^{\circ}$ took much less than 1 sec. and, though exposure to isopentane killed a few bacteria ( $97 \%$ viability reduced to $95 \%$ ), deep freezing had no subsequent effect ( $95 \%$ viability).

\section{Penetration by protective agents}

The substances tested as protective agents against freezing damage were chosen as three likely to penetrate freely into the cell cytoplasm (glycerol, diethylene glycol, erythritol) and three unlikely to do so on a large scale (glucose, sucrose, polyethylene glycol). It was necessary to know whether in fact these materials behaved as expected. Mager, Kuczynski, Schatzberg \& Avi-dor (1956) showed that the optical densities of live bacterial suspensions in osmotically active solutions were greater than in distilled water, and interpreted this 'optical effect' as an increase in the refractive index of the cytoplasm consequent on its adjustment to the osmotic pressure of the environment. Materials that penetrate to the cell cytoplasm should be osmotically neutral and should show no such effect. The permeability of the bacteria used in this work was examined by using this principle, after preliminary tests had shown that a maximum optical effect occurred with $0 \cdot 4 \mathrm{M}-\mathrm{NaCl}$ (optical density in $0 \cdot 4 \mathrm{M}-\mathrm{NaCl}=130 \%$ that in distilled $\mathrm{H}_{2} \mathrm{O}$ ). The optical densities of suspensions equivalent to $0.13 \mathrm{mg}$. dry wt., $95-100 \%$ viable bacteria $/ \mathrm{ml}$. medium were compared in $0.4 \mathrm{M}$ solutions and in distilled water; the extents of the optical effect were: glycerol, $-4 \%$; diethylene glycol, $-1.6 \%$; $i$-erythritol, $+2 \%$; glucose, $+15 \%$; $\mathrm{NaCl}$ control, $+34 \%$. Some of the optical effect of glucose was doubtless masked by the relatively high molar refractive increment of glucose; with sucrose this property rendered the method inapplicable (optical effect $-15 \%$ ), and its penetration was investigated by using the thick suspension technique of Mitchell \& Moyle (1956) and estimating sucrose refractometrically. The sucrose-penetrable space in bacteria centrifuged to constant volume in $0.1 \mathrm{M}$-sucrose was $19 \%$ of their total volume. This value is incompatible with penetration into the cells. Theoretically, the intercellular water between close-packed bacteria should occupy about $26 \%$ of the volume and 
the inter + intracellular water about 70\% (Mitchell \& Moyle, 1956). Penetration by polyethylene glycol was not studied; it was assumed not to penetrate the organisms because of its high mean molecular weight of 10,000 .

\section{Storage of frozen populations}

Batches of frozen beads of bacterial suspension were transferred to cold, closed test tubes and stored at $-\mathbf{2 0}^{\circ}$ in a deep freezer to examine their storage lives with various protective agents. The storage lives were dramatically different (Table 2).

Table 2. Cold storage of frozen suspensions of Aerobacter aerogenes

Suspensions of Aerobacter aerogenes (equiv. $1 \mathrm{mg}$. dry wt. organism/ml.) grown as in Table 1 were suspended in the $10 \%$ aqueous solutions below, frozen as beads of about $0.05 \mathrm{ml}$. in liquid nitrogen and stored in closed tubes at $-20^{\circ}$. Individual beads were thawed by dropping into $2.5 \mathrm{ml}$. buffered saline at 18 to $20^{\circ}$ and the viabilities of the thawed suspensions measured by slide culture.

Solute

\section{Glycerol}

Polyethylene glycol

Diethylene glycol

Sucrose

Glucose

$i$-Erythritol

Glycerol*

\section{Davs}

Viability (\%)

Days

Viability (\%)

Days

Viability (\%)

Hours

Hours

Viability (\%)

Minutes

Viability (\%)

Days

Viability (\%)
Storage life at $-20^{\circ}$

\begin{tabular}{|c|c|c|c|c|c|c|}
\hline 0 & 2 & 6 & 10 & 20 & 27 & 40 \\
\hline 95 & 92 & 91 & 86 & 92 & 85 & 85 \\
\hline 0 & 0.7 & $1 \cdot 7$ & 4 & 16 & & \\
\hline 96 & 80 & 87 & 70 & 65 & & \\
\hline 0 & 2 & 16 & & & & \\
\hline 98 & 72 & 53 & & & & \\
\hline 0 & 2 & 5 & 8 & $11 \cdot 7$ & 24 & \\
\hline 98 & 78 & 72 & 60 & 25 & 25 & \\
\hline 0 & 2 & 4.5 & $7 \cdot 5$ & 16.5 & & \\
\hline 92 & 31 & 22 & 19 & 12 & & \\
\hline 0 & 5 & 10 & 15 & 20 & 100 & \\
\hline 94 & 98 & 9 & 3 & 4 & 1 & \\
\hline 0 & 0.7 & $1 \cdot 8$ & $4 \cdot 8$ & 9 & $15 \cdot 6$ & 29 \\
\hline 98 & 94 & 96 & 93 & 94 & 86 & 86 \\
\hline
\end{tabular}

* In this case the suspension contained equiv. $10 \mathrm{mg}$. dry wt. organism $/ \mathrm{ml}$.

Even after 40 days a majority of those populations frozen in glycerol were viable, whereas after $10 \mathrm{~min}$. the majority of those frozen in erythritol were dead. It is probable that the population taken at $5 \mathrm{~min}$. from the erythritol series had not completely warmed up from the $-200^{\circ}$ of liquid nitrogen to the $-20^{\circ}$ of the storage cabinet. Other materials gave intermediate storage lives. The data given in Table 2 are representative of at least two sets of experiments with each storage medium; erythritol was tested three times owing to the exceptionally short storage life observed with it; polyethylene glycol was tested three times since on one occasion death was more rapid than that recorded in Table 2 (viability dropped from 87 to $20 \%$ between the 24th and 40th hours). Beads of glycerol, polyethylene glycol and sucrose took on a damp appearance after 1-3 days' storage; those of erythritol and diethylene glycol did not. None of the beads appeared vitreous after freezing in comparison with a frozen solution of $50 \%$ glycerol. Some indication that the population effect of Major et al. (1955) did not occur on storage with glycerol is indicated by the experiment also recorded in Table 2 in which a frozen population equiv. $10 \mathrm{mg}$. dry wt. organism/ ml. survived at $-20^{\circ}$ in a manner similar to one equiv. $1 \mathrm{mg}$. dry wt. $/ \mathrm{ml}$. 


\section{DISCUSSION}

The mechanism of killing by freezing and of protection of organisms from such injury is complex and has been discussed by several of the workers mentioned in the Introduction. For the particular case of bacteria there is reason to believe that mechanical injury by ice crystals is not responsible (Harrison \& Cerroni, 1956). Evidence exists that the major contributory factor is osmotic shock (Harrison, 1956) though Mazur's (1960) findings do not support this view. By analogy with the protective action of glycerol on erythrocytes (Lovelock, 1953), it has been suggested that partial dehydration by penetration of glycerol into the cell cytoplasm is necessary for bacteria to survive freezing (Hollander \& Nell, 1954). We shall restrict our discussion to pointing out where certain of our data are relevant to these questions.

The necessity for penetration by the protective substance. With our populations, glycerol, erythritol and diglycol penetrated the bacterial cytoplasm. Glucose and sucrose did not, and it is not likely that the high-molecular weight polyglycol did so. As protective agents all these substances were effective; hence penetration is irrelevant to protection against killing by freezing.

The necessity for partial dehydration. The two classes of protective agent, penetrating and non-penetrating, have in common that they could both dehydrate the cell cytoplasm; one class would do this by osmotic dehydration, the other class would cause a more modest dehydration by physical dilution of the cell cytoplasm. If dehydration were necessary for protection, a high molecular weight substance should have no protective effect owing to its low osmotic pressure in $10 \%$ solution; yet polyethylene glycol protected perfectly well.

Freezing as a form of osmotic damage. The protective action of materials that do not penetrate the organisms yet which were present at initially high molarities (glucose or sucrose) makes it unlikely that concentration of solute during freezing exerted any lethal effect on our populations. In addition, survival in distilled water ought to be maximal if osmotic damage of this kind were relevant, but with our population distilled water was as lethal an environment as broth or the basal medium. This observation conflicts with those recorded by Harrison (1956) and Clement (1961), who found distilled water a relatively innocuous environment for freezing; the difference may be due to our use of a different species, or to the fact that our organisms were in a state corresponding to the logarithmic phase of growth of a batch culture whereas those studied by Harrison and Clement were stationary. The phase of growth is known to influence markedly the sensitivity of bacteria to damage by freezing (Toyokama \& Hollander, 1956).

Metabolic damage after freezing and thawing. Though protected populations were still viable after this treatment, it is clear that they sustained some damage since the deep-frozen organisms died more rapidly than controls in starvation conditions and had a reduced rate of substrate oxidation. Squires \& Hartsell (1955) reported that freezing and storage altered the lags and growth rates of their bacteria and Straka \& Stokes (1959) reported a 'nutritional injury' of frozen bacteria whereby a proportion of the population, after thawing, was found to be nutritionally exacting for materials of a peptide character.

Toxicity of the preserving agent. Though glycerol is widely used as a protective agent, toxic effects at the necessary concentration have been recorded. For example, 
Quadling (1960) reported about $39 \%$ survival after exposure of Xanthomonas phaseoli to $15 \%$ glycerol broth though the whole $39 \%$ then survived freezing and thawing. Our populations were not affected by 10 or $15 \%$ glycerol (though $30 \%$ aqueous glycerol killed $60 \%$ of the organisms) but in other tests we have observed such toxicity. Vibrio anguillarum (NCMB 6) fell in viability from 55 to $40 \%$; Chromobacterium violaceum (NCIB 8182) fell from 92 to $87 \%$; Escherichia coli (Jepp) was uninfluenced (94\% in control, $96 \%$ in $10 \%$ glycerol). With our population of Aerobacter aerogenes slight toxicities occurred with certain substitutes for glycerol (Table 1) but, in agreement with Quadling, the survivors of such toxicity were protected from freezing damage.

Distinction between freezing and cold storage. Though several different chemicals protected our organisms against freezing damage, the storage life of a frozen suspension at $-20^{\circ}$ was very much influenced by the nature of the protective agent; periods of maximum survival ranged from a few minutes in erythritol to many days in glycerol. Speculation about the reasons for these differences would not be fruitful on the data available, but it is obvious by arguments similar to those above that penetration or osmotic dehydration are irrelevant to store life in the frozen state. Our observations suggest that the population effect reported by Major et al. (1955) is not involved in the freezing or thawing processes. It is probably a phenomenon that only becomes manifest on storage and even then may not occur in protective environments such as $10 \%$ glycerol.

Effect of freezing rate. In the protective environment of $10 \%$ glycerol we could detect no significant effect of rate of freezing, though our experiments were cruder than those of Mazur et al. (1957) in that we knew the freezing rates only roughly. Mazur et al.'s experiments were concerned with survival in a non-protective environment, and in such conditions our organism seemed to differ from Pasteurella tularensis, since with Aerobacter aerogenes slow freezing of $10 \mathrm{ml}$. samples in buffer in solid $\mathrm{CO}_{2}$ was more lethal (viability dropped from 95 to $1 \%$ ) than rapid freezing of similar samples in liquid $\mathrm{N}_{2}(32-39 \%$ in Table 1$)$.

Record \& Taylor (1960) showed that organisms which have been dried in sucrose solutions are subject to internal diffusion pressures on reconstitution due to sugar trapped between cell wall and protoplast membrane. Such diffusion pressures may cause disruption and death of the organisms; high molecular weight substances protect by decreasing the amount of sugar so trapped. During the present work diffusion pressures must have arisen when frozen preparations were in process of thawing, particularly during the experiments involving glucose and sucrose; we attribute the fact that our organisms survived freezing and immediate thawing to our use of solutions which were unlikely to have become as concentrated during this period as they would have done during a treatment that involved drying. The observations reported here help to resolve the paradox mentioned in the introduction. Moses (1955) and Postgate (1960) suspended their organism in very dilute buffer ( $0.0625 \mathrm{M}$ $\mathrm{KH}_{2} \mathrm{PO}_{4}$ ) and Wade \& Lovett (1961) used distilled water containing traces of salts carried over in the washing procedure. These are among the most lethal environments encountered in the present work. Even broth had some protective effect, and the majority of studies in which high survivals have been shown were concerned with organisms suspended in such partially protective environments. Broadly speaking, one might expect maximum destruction of organisms on freezing in 
'saline', minimum damage in a $10 \%$ solution of a non-electrolyte, intermediate degrees of damage in ordinary bacteriological media, distilled water or tap water.

We are indebted to Dr G. D. Floodgate for a preview of Floodgate \& Hayes (1961) and to Dr B. R. Record for helpful discussions.

\section{REFERENCES}

Clement, M. T. (1961). Effects of freezing, freeze-drying and storage in the freeze-dried and frozen state on viability of Escherichia coli cells. Canad. J. Microbiol. 7, 99.

Floodgate, G. D. \& Hayes, P. R. (1961). The preservation of marine bacteria. J. appl. Bact. 24 (in the Press).

Fox, M. S. \& Hotchiss, R. D. (1957). Initiation of bacterial transformation. Nature, Lond. 179, 1322.

Fry, R. M. \& Greaves, R. I. N. (1951). The survival of bacteria during freezing and after drying. J. Hyg., Camb. 49, 220.

Gorrill, R. H. \& MCNrel, E. M. (1960). The effect of cold diluent on the viable count of Pseudomonas pyocyanea. J. gen. Microbiol. 22, 437.

Haines, R. B. (1938). The effect of freezing on bacteria. Proc. roy. Soc. B, 124, 451.

Harrison, A. P. (1955). Survival of bacteria on repeated freezing and thawing. J. Bact. 70, 711.

Harrison, A. P. (1956). Causes of death of bacteria in frozen suspensions. Antonie Van Leeurvenhoek J. Microbiol. Serol. 22, 407.

Harrison, A. P. \& Cerroni, R. E. (1956). Fallacy of 'crushing death' in frozen bacterial suspension. Proc. Soc. exp. Biol., N.Y. 91, 577.

Hegarty, C. P. \& Weeks, O. B. (1940). Sensitivity of Escherichia coli to cold-shock during the logarithmic growth phase. J. Bact. 39, 475.

Herbert, D., Elsworth, R. \& Telling, R. C. (1956). The continuous culture of bacteria; a theoretical and experimental study. J. gen. Microbiol. 14, 601.

Hollander, D. H. \& Nell, E. E. (1954). Improved preservation of Treponema pallidum and other bacteria by freezing with glycerol. Appl. Microbiol. 2, 164.

HowARD, D. H. (1956). The preservation of bacteria by freezing in glycerol broth. J. Bact. $71,625$.

LovELOCK, J. E. (1953). The mechanism of the protective action of glycerol against haemolysis by freezing and thawing. Biochim. biophys. Acta, 11, 28.

LuYeT, B. J. \& Gehenio, P. M. (1940). Life and Death at Low Temperatures. Normandy, Mo., U.S.A.: Biodynamica.

Mager, J., Kuczynski, M., Schatzberg, G. \& Avi-dor, Y. (1956). Turbidity changes in bacterial suspensions in relation to osmotic pressure. J. gen. Microbiol. 14, 69.

Major, C. P., McDougal, J. D. \& Harrison, A. P. (1955). The effect of initial cell concentration upon survival of bacteria at $-22^{\circ}$ C. J. Bact. 69, 244.

Mazur, P. (1960). Physical factors implicated in the death of micro-organisms at sub-zero temperatures. Ann. N.Y. Acad. Sci. 85, 610.

Mazur, P., Rhian, M. A. \& Mahlandt, B. G. (1957). Survival of Pasteurella tularensis in gelatin-saline after cooling and warming at sub-zero temperatures. Arch. Biochem. 71, 31.

MeYNeld, G. G. (1958). Effect of sudden chilling on Escherichia coli. J. gen. Microbiol. 19, 380.

Mrtchell, P. \& Moyle, J. (1956). Osmotic function and structure in bacteria. In Bacterial Anatomy. Symp. Soc. gen. Microbiol. 6, 150.

Moses, V. (1955). Tricarboxylic acid cycle reactions in the fungus Zygorrhynchus moelleri. J. gen. Microbiol. 13, 235.

Norris, K. P. \& Powell, E. O. (1961). Improvements in determining total counts of bacteria. J. R. micr. Soc. 80 (in the Press).

Polge, C., Smith, A. U. \& PARKes, A. S. (1949). Revival of spermatozoa after vitrification and dehydration at low temperatures. Nature, Lond. 164, 666. 
Postgate, J. R. (1960). Cytochrome $c_{3}$. Proceedings of the Haematin Enzyme Symposium, Canberra. Ed. J. E. Falk, M. R. Lemberg \& R. K. Morton. London: Pergamon Press. Postgate, J. R., Crumpton, J. E. \& Hunter, J. R. (1961). Measurement of bacterial viabilities by slide culture. J. gen. Microbiol. 24, 15.

Quadling, C. (1960). Preservation of Xanthomonas by freezing in glycerol broth. Canad. J. Microbiol. 6, 475.

Record, B. R. \& TAYlor, R. (1953). Some factors influencing the survival of Bacterium coli on freeze drying. J. gen. Microbiol. 9, 475.

Record, B. R. \& Taylor, R. (1960). Survival of bacteria on drying in sugar/protein mixtures. Nature, Lond. 185, 944.

Sanderson, E. S. (1925). Effect of freezing and thawing on the bacteriophage. Science, 62, 377.

Sfrerman, J. M. \& Cameron, G. M. (1934). Lethal environmental factors within the neutral range of growth. J. Bact. 27, 341.

Smith, E. F. \& Swingle, D. B. (1905). Der Einfluss des Gefrierens auf Bakterien. Zbl. Bakt. 37, 357.

Squires, R. W. \& Hartsell, S. E. (1955). Survival and growth initiation of defrosted Escherichia coli as affected by frozen storage menstrua. Appl. Microbiol. 3, 40.

Straka, R. P. \& Stokes, J. L. (1959). Metabolic injury to bacteria at low temperatures. J. Bact. 78, 181.

Tanguay, A. E. (1959). Preservation of microbiological assay organisms by direct freezing. Appl. Microbiol. 7, 84.

Toyokama, K. \& Hollander, D. H. (1956). Variation in sensitivity of Escherichia coli to freezing damage during the growth cycle. Proc. Soc. exp. Biol., N.Y. 92, 499.

Wade, H. E. \& LoverT, S. (1961). Polynucleotide phosphorylase in ribosomes from Escherichia coli. Biochem. J. 81, 319.

Wieser, R. S. \& Osterud, C. M. (1945). Studies on the death of bacteria at low temperatures. 1. The influence of the intensity of the freezing temperature, repeated fluctuations of temperature, and the period of exposure to freezing temperatures on the mortality of Escherichia coli. J. Bact. 50, 413.

Wood, T. H. \& Rosenberg, A. M. (1957). Freezing in yeast cells. Biochim. biophys. Acta, 25, 78. 